\title{
Análise numérica de pilares de aço com restrições axial e rotacional em situação de incêndio
}

\author{
Caroline Rainha Bubach ${ }^{1}$, Macksuel Soares de Azevedo², Valdir Pignatta Silva ${ }^{3}$ \\ ${ }^{1}$ Universidade Federal do Espirito Santo, Av. Fernando Ferrari, 514. Vitória - ES. \\ CEP 29.075-910, carolinebubach@gmail.com \\ ${ }^{2}$ Universidade Federal do Espirito Santo, Av. Fernando Ferrari, 514. Vitória - ES. \\ CEP 29.075-910, macksuel.azevedo@gmail.com \\ ${ }^{3}$ Escola Politécnica da Universidade de São Paulo, Av. Professor Almeida Prado, \\ 83. São Paulo-SP. CEP 05.508-010, valpigss@usp.br
}

\section{Numerical analysis on axially and rotationally restrained steel columns in fire}

\begin{abstract}
Resumo
O desempenho de um pilar de aço em situação de incêndio é influenciado por sua interação com as vigas, lajes e pilares da estrutura envolvente, pois as diferentes deformações térmicas desenvolvidas entre os elementos aquecidos e os elementos que permanecem relativamente frios desenvolvem restrições axiais e rotacionais no pilar, alterando sua temperatura crítica e sua resistência a elevadas temperaturas. O presente trabalho tem o objetivo de simular numericamente o comportamento de pilares de aço de seção I em situação de incêndio com restrições axial e rotacional via método dos elementos finitos utilizando o programa de computador ANSYS v17.0
\end{abstract}

Palavras-chave: Incêndio. Aço. Pilares. Restrição axial. Restrição rotacional.

\begin{abstract}
The performance of a steel column in fire is highly influenced by its interaction with the beams, slabs and columns of the surrounding structure, because the different thermal strains developed between the heating elements and the elements that remain relatively cold develop axial and rotational restraints in the column that modify its critical temperature and fire resistance. This study aims to numerically validate the behavior of I section steel columns in fire with axial and rotational restraint using the finite element program ANSYS v17.0.
\end{abstract}

Keywords: Fire. Steel. Columns. Axial restraint. Rotational restraint 


\section{Introdução}

De acordo com Ali e O'Connor (2001), quando ocorre incêndio em um compartimento de uma edificação, outras partes não expostas permanecem relativamente frias, gerando restrições a deformações térmicas nos elementos estruturais. Portanto, o comportamento de pilares de aço em situação de incêndio é influenciado pela interação entre os elementos aquecidos e a estrutura envolvente com temperatura inferior, gerando restrições axiais e rotacionais. A restrição axial se opõe à expansão térmica do pilar e a restrição rotacional reduz a rotação das extremidades do pilar. A presença dessas restrições pode gerar substanciais forças adicionais, influenciando na temperatura crítica e na resistência a elevadas temperaturas dos pilares de aço.

Segundo Wang (2002), os possíveis efeitos gerados no comportamento de um pilar aquecido, devido à interação entre ele e a estrutura envolvente, são: i) Alteração na força axial do pilar devido à restrição axial de sua expansão térmica, como mostra a Figura 1 (a); ii) Alteração no comprimento de flambagem do pilar devido à restrição rotacional variável do pilar; iii) Alteração no momento fletor solicitante do pilar devido à rigidez variável do pilar relativo à estrutura adjacente; iv) Alteração no momento fletor solicitante do pilar devido à força lateral das vigas adjacentes termicamente restringidas, como mostrado na Figura 1 (b); v) Alteração no momento fletor solicitante do pilar decorrente do efeito da não linearidade geométrica, ou seja, a influência da deformação do pilar devido à expansão térmica de vigas adjacentes, como mostrado na Figura 1 (c).

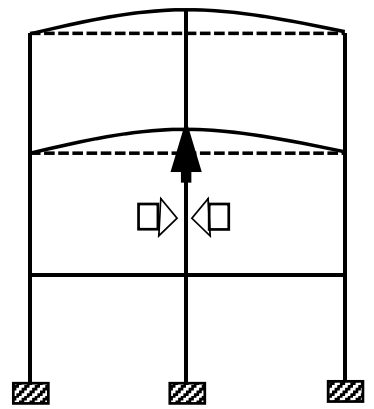

a) Efeito da restrição à expansão térmica

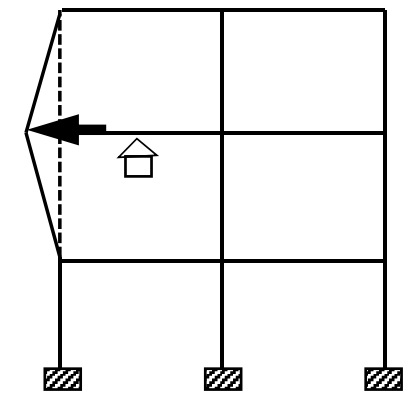

b) Efeito causado por vigas termicamente restringidas

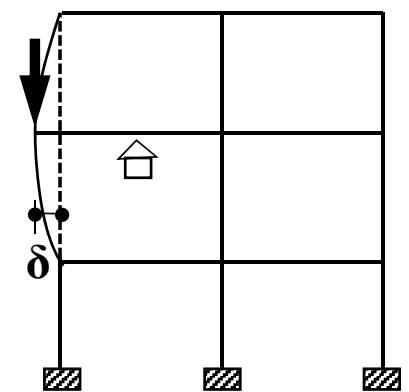

c) Efeito $P-\delta$

Figura 1 - Influência da estrutura adjacente no comportamento de um pilar aquecido Fonte: Wang (2002) 
Segundo Shepherd e Burgess (2011), a restrição axial de um pilar de aço aquecido é gerada por meio das ligações entre as vigas e as lajes dos pisos superiores e o pilar contínuo, bem como pela rigidez ao cisalhamento da estrutura como um todo. Esses elementos estruturais irão resistir à expansão térmica do pilar exercendo uma força na extremidade de qualquer viga ligada a ele e qualquer pilar diretamente superior.

No caso de uma estrutura com somente um pavimento, com incêndio ocorrendo em um compartimento onde existe apenas um pilar, nota-se que os outros pilares da estrutura, que não estão no compartimento incendiado permanecerão frios. Assim, as vigas que ligam o pilar aquecido aos outros pilares serão submetidas a movimentos verticais diferenciais em suas extremidades, pois um pilar estará expandindo termicamente e os outros permanecerão inalterados. Dessa forma, as vigas serão induzidas à flexão e, portanto, irão exercer uma força de restrição no pilar aquecido, como mostrado na Figura 2 (a).

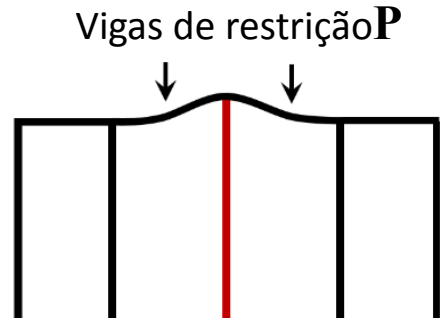

a) Único pilar aquecido

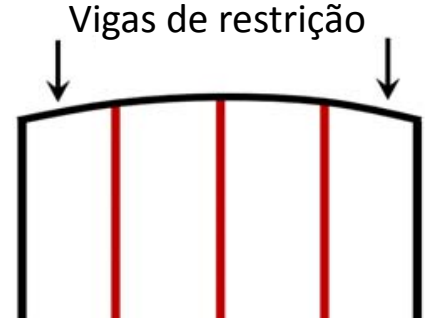

b) Três pilares aquecidos

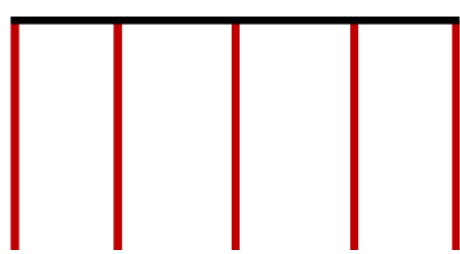

c) Todos os pilares aquecidos

Figura 2 - Incêndio em uma estrutura de um único pavimento Fonte: Shepherd e Burgess (2011)

Entretanto, ao considerar três pilares no interior do compartimento incendiado, os mesmos estarão aquecidos à uma variação de temperatura semelhante, e assim, as extremidades das vigas ligadas ao pilar central serão submetidas ao mesmo movimento vertical e nenhuma força de restrição será introduzida nesse pilar. Porém, haverá naturalmente uma força de restrição sob os outros dois pilares aquecidos, como mostrado na Figura 2 (b). Somente quando um andar inteiro é aquecido à exatamente a mesma taxa de temperatura, todos os pilares ficarão livres da adição de forças de restrição, visto que irão expandir termicamente juntos e não haverá nenhum movimento vertical relativo nas vigas conectadas a eles. Esse último caso está apresentado na Figura 2 (c). 
Ao considerar uma estrutura com dois ou mais pavimentos, a situação é similar, porém, as forças de restrição geradas devido à expansão térmica do pilar, ou grupo de pilares, serão transmitidas ao longo dos pilares do pavimento superior para as vigas superiores. Entretanto, somente uma parcela do movimento atinge essas vigas, visto que os pilares superiores apresentam rigidez axial, mas, uma vez que isso acontece, esse movimento é resistido por flexão exatamente da mesma forma que ocorre nas vigas do pavimento inferior. Essa situação é apresentada pela Erro! Fonte de referência não encontrada.. Geralmente, quanto maior a rigidez de restrição axial, maior será a força de compressão adicional e menor será a temperatura que causará a instabilidade dos pilares restringidos. Um pilar mais esbelto tem menor capacidade de suporte de carga e também atrai uma maior adição de força de compressão devido a uma maior restrição térmica. Ambos efeitos levam a uma temperatura menor que causará a instabilidade de pilares com restrição axial. De acordo com Neves (1995), a taxa de crescimento das forças de restrição geradas depende, inicialmente, da rigidez da estrutura envolvente. Então, com o aumento da temperatura, e a consequente degradação das propriedades do material (resistência e módulo de elasticidade), essa taxa se tornará gradualmente menor. Com o início do escoamento do aço, as forças de restrição crescem ainda mais lentamente. Dessa forma, o desenvolvimento das forças de restrição em pilares em situação de incêndio é representado por um aumento inicial seguido por uma fase de redução, conforme mostrado na Figura 4.

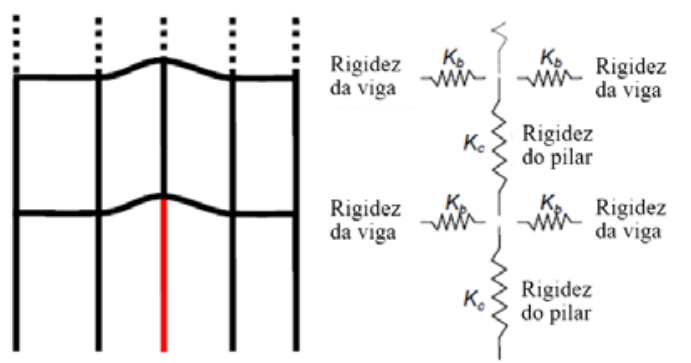

Figura 3 - Incêndio em uma estrutura de múltiplos pavimentos Fonte: Shepherd e Burgess (2011).

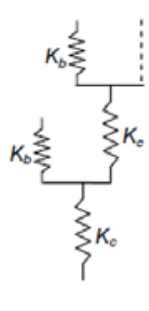

Figura 4 - Desenvolvimento das forças de restrição Fonte: Neves (1995)

Assim, visto que a velocidade de aumento das forças de restrição dependerá da rigidez da estrutura envolvente, em Shepherd e Burgess (2011) é destacado que, mesmo utilizando pilares com seções transversais iguais, a capacidade resistente à 
flexocompressão à temperatura ambiente, cujo valor será idêntico nos pilares considerados, poderá ser atingida em diferentes temperaturas. Isso ocorre, porque pilares altamente restringidos apresentam rápido acréscimo das forças de restrição e, então, atingem sua capacidade resistente em temperaturas inferiores à de pilares menos restringidos. Dessa forma, ao atingir sua capacidade resistente, as propriedades do material dos pilares mais restringidos não sofreram muita degradação em relação aos menos restringidos, e assim, a rigidez é relativamente maior e um elevado nível de força pode ser alcançado no pilar. O mesmo não ocorre em pilares com baixos níveis de restrição, pois, para que atinjam sua capacidade resistente, é necessário que estejam muito aquecidos e, nesse estágio, as propriedades do material já foram suficientemente degradadas de forma a resultar em valores muito menores de força de restrição. Então, com a elevação da temperatura, as forças de restrição aumentam até atingir um valor máximo, seguido de uma fase de declínio, e o valor da força que causa a instabilidade diminui devido à degradação das propriedades do material. Em algum momento, a combinação desses dois fatores inicia o colapso do pilar, que passa a não ser mais capaz de cumprir o papel para o qual foi projetado. A força axial não mais suportada pelo pilar tende a ser redistribuída para outros elementos da estrutura envolvente. Caso a estrutura não possua rigidez suficiente para garantir caminhos alternativos para a redistribuição das forças, o colapso pode se espalhar a partir da origem do incêndio e levar a um colapso progressivo. Ao considerar o comportamento de pilares axialmente restringidos, é importante destacar a distinção entre a temperatura que leva à instabilidade e a temperatura de colapso do pilar. Franssen (2000) sugere que é apropriado definir a temperatura de colapso como aquela em que a força axial no pilar retorna ao seu valor original.

Wang (2002), analisando o comportamento de pilares ideais, considera que a estrutura que fornece a restrição à expansão térmica antes da flambagem (bifurcação de equilíbrio), posteriormente, também fornece ao pilar restrição suficiente para permitir sua estabilidade, embora com força reduzida. Ou seja, diferentemente do que ocorre à temperatura ambiente, em que a deformada pós-crítica é estável, no caso em estudo, a deformada pós-crítica é de equilíbrio instável e a barra procura voltar à posição inicial, o que é favorável à estabilidade do pilar. A Figura 5 ilustra a relação entre a força e a 
temperatura de um pilar axialmente restringido, em regime elástico-linear, sem imperfeição, ou seja, pilar ideal. Pode ser dividida em três estágios: pré-crítico, flambagem e pós-crítico.

Quando ocorre a flambagem do pilar, pode-se considerar que o pilar sofre um repentino movimento lateral acompanhado por uma contração axial, como mostrado na Figura 6 (a).

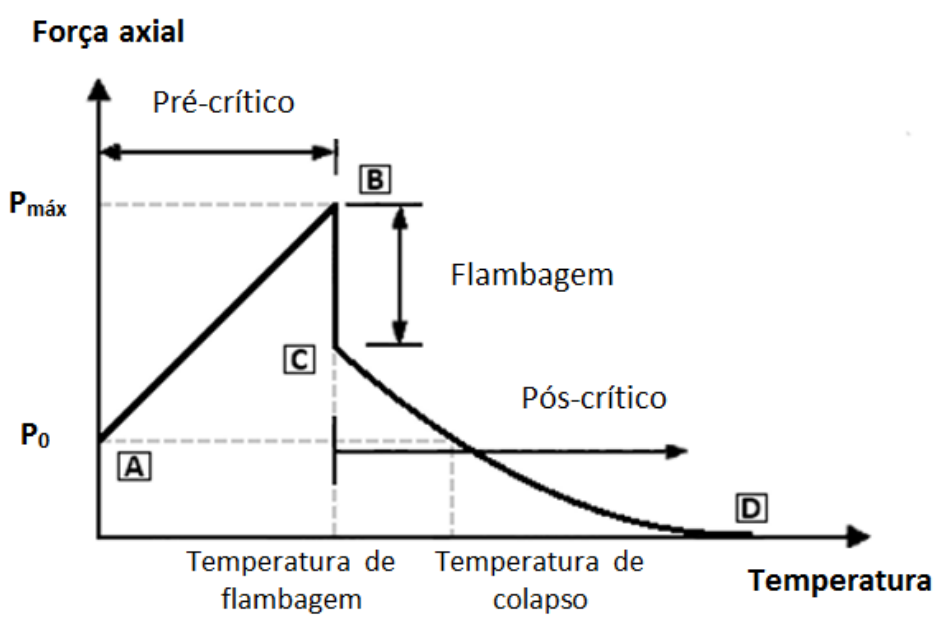

Figura 5 - Relação entre a força e temperatura de pilar ideal com restrição em incêndio Fonte: Wang (2002)

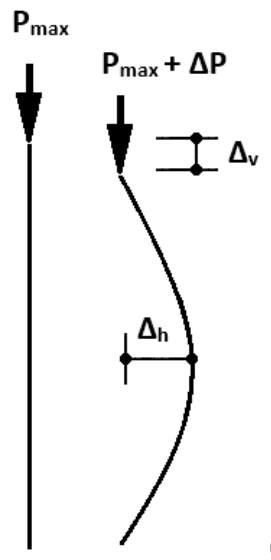

(a)

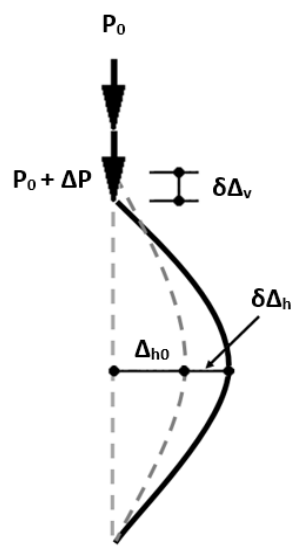

(b)

Figura 6 - Força e deslocamento durante as fases de deformação pela flambagem e pós-crítica

Fonte: Wang (2002)

Na fase pós-crítica, com o aumento da temperatura do pilar, sua deformação axial consiste em três fases: expansão térmica livre, aumento da deformação mecânica e contração adicional do pilar causada pela adicional deformação lateral, como mostrado na Figura 6 (b). Para pilares reais, o diagrama força-deslocamento tem uma variação mais suave e se apresenta conforme a Figura 4. 
Além da restrição axial, a diferença de temperatura entre o pilar aquecido e a estrutura em que ele está inserido pode gerar também restrições rotacionais. A restrição rotacional de pilares em situação de incêndio reduz seu comprimento de flambagem, e aumenta sua temperatura de colapso. Isso ocorre porque a rigidez de um pilar a elevadas temperaturas é reduzida, e, se a estrutura envolvente permanecer fria, retendo, assim, suas propriedades originais do material, sua rigidez poderá se tornar muito alta em relação à do pilar, de forma a fornecer um alto nível de restrição rotacional ao pilar aquecido. A estrutura que fornece a restrição rotacional ao pilar pode ser tanto as vigas e lajes adjacentes quanto os pilares contínuos a partir das extremidades do pilar aquecido, ou ambos. Se as ligações viga-pilar forem rotuladas, não oferecerão nenhuma restrição rotacional ao pilar aquecido. Porém, se essas ligações forem rígidas ou semirrígidas, as vigas e lajes adjacentes fornecerão alguma restrição rotacional ao pilar, que dependerá da taxa de aquecimento dos elementos.

Webber et al. (2015) estudou analiticamente a influência da rigidez dos pilares adjacentes no comprimento de flambagem de um pilar inserido em uma estrutura de múltiplos pavimentos, comparando os resultados obtidos pelo método do comprimento efetivo com os resultados obtidos numericamente usando o programa de análise estrutural Autodesk Robot Structural Analysis. Na Figura 7 observou-se que, quando os pilares $A B$ e $C D$ são mais rígidos que o pilar $B C$, a rotação nos pontos $B$ e $C$ são reduzidas e o pilar BC possui menor comprimento de flambagem.
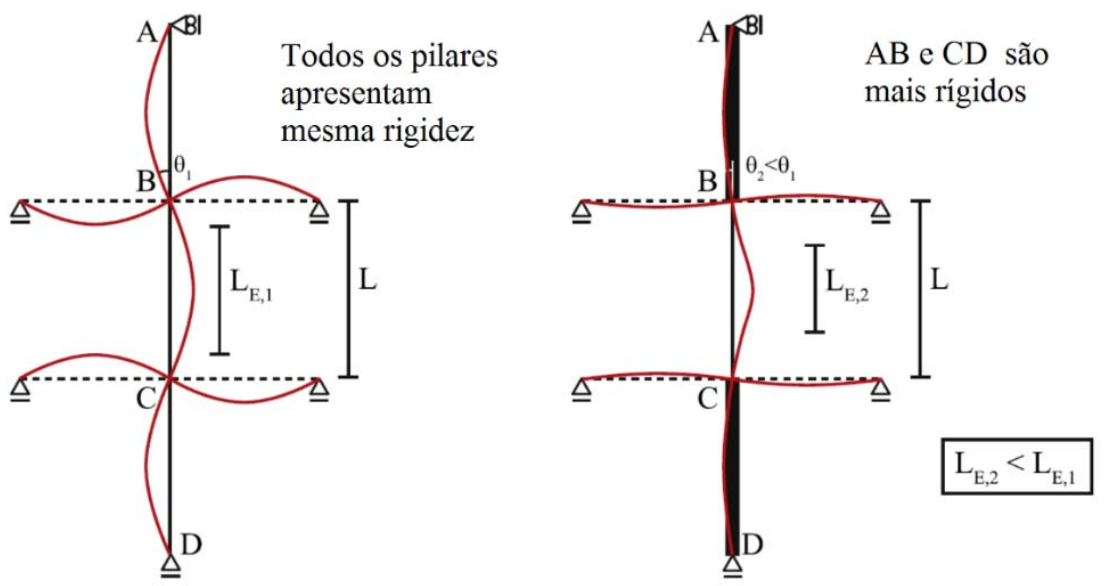

Figura 7 - Contribuição dos pilares adjacentes à rigidez rotacional nos apoios Fonte: Webber et al. (2015).

Analogamente à análise apresentada por Webber et al. (2015), a redução do comprimento de flambagem em pilares em situação de incêndio ocorre devido à 
diferença de rigidez entre o pilar localizado no compartimento incendiado, cuja resistência e módulo de elasticidade foram reduzidos, e os pilares adjacentes que permaneceram frios. Dessa forma, o nível de restrição rotacional do pilar aquecido aumentará e seu comprimento de flambagem será reduzido. Uma situação similar ocorre para vigas e lajes adjacentes.

No Brasil, apesar do crescimento do uso de estruturas de aço, ainda são poucas as pesquisas sobre o comportamento de pilares de aço restringidos em situação de incêndio. Assim, esta pesquisa tem por objetivo simular o comportamento de pilares de aço em situação de incêndio por meio do desenvolvimento de análise numérica, via método dos elementos finitos utilizando o programa de computador ANSYS v17.0, para criar um modelo numérico que servirá de base para novas pesquisas relacionadas ao tema, considerando níveis de restrições axial e rotacional e a curva de incêndio-padrão ISO 834.

\section{Modelo experimental de referência}

Para a validação do modelo numérico elaborado no presente trabalho foram utilizados os dados experimentais obtidos por Correia (2011) em ensaios de pilares de aço com restrição axial e rotacional em situação de incêndio, com forças centradas. A Figura 8 apresenta a estrutura de restrição tridimensional cuja função foi simular a rigidez da estrutura ao redor do pilar em situação de incêndio e era composta por quatro pilares, duas vigas inferiores e duas vigas superiores que são dispostas em direções ortogonais. O uso de uma estrutura de restrição tridimensional permitiu levar em conta não somente a restrição axial, mas também a restrição rotacional como observado em uma estrutura real. Entre o pilar ensaiado e a viga superior da estrutura de restrição foi colocado um dispositivo especial para medir as forças de restrição geradas durante o ensaio. Esse dispositivo era formado por um tubo de aço de alta resistência, o qual foi rigidamente conectado às vigas superiores da estrutura de restrição, e por um cilindro maciço de aço, o qual foi conectado à extremidade superior dos elementos a serem ensaiados, posicionado dentro do tubo.

As vigas da estrutura de restrição possuíam furos em diferentes distâncias em relação ao centro da estrutura, de forma a gerar diferentes valores de rigidez axial e rotacional 
no pilar ensaiado, como mostra a Figura 9. Os valores de rigidez axial utilizados no ensaio foram $13000 \mathrm{kN} / \mathrm{m}, 45000 \mathrm{kN} / \mathrm{m}$ e $128350 \mathrm{kN} / \mathrm{m}$ e os respectivos valores de rigidez rotacional foram $4827.5 \mathrm{kNm} / \mathrm{rad}$., $5622 \mathrm{kNm} / \mathrm{rad}$. e $7844 \mathrm{kNm} / \mathrm{rad}$.

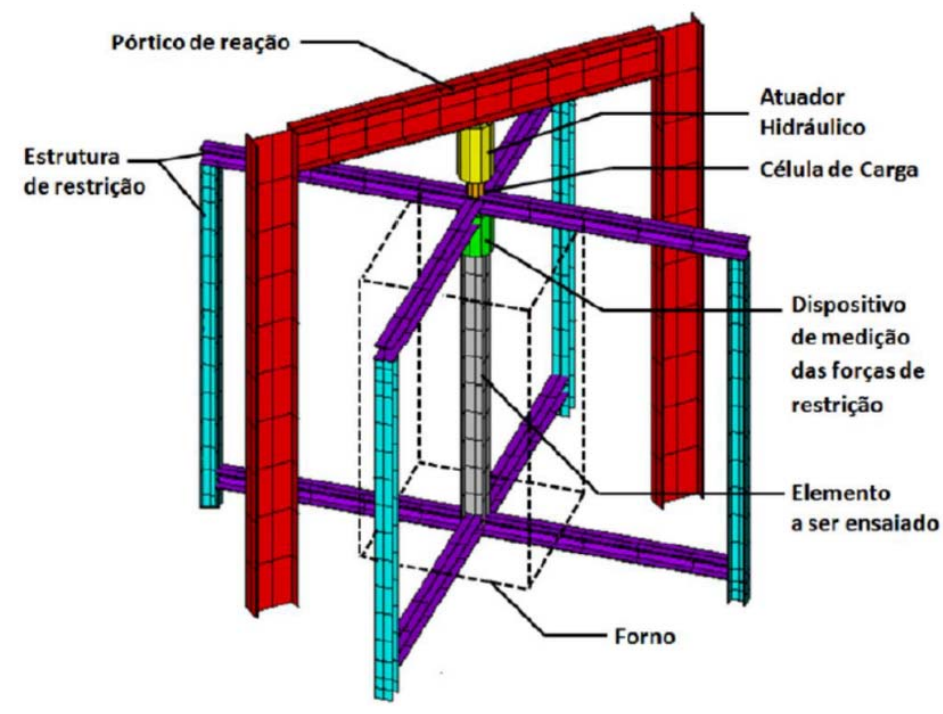

Figura 8 - Visão geral da estrutural de restrição Fonte: Almeida (2012)

As vigas da estrutura de restrição possuíam furos em diferentes distâncias em relação ao centro da estrutura, de forma a gerar diferentes valores de rigidez axial e rotacional no pilar ensaiado, como mostra a Figura 9. Os valores de rigidez axial utilizados no ensaio foram $13000 \mathrm{kN} / \mathrm{m}, 45000 \mathrm{kN} / \mathrm{m}$ e $128350 \mathrm{kN} / \mathrm{m}$ e os respectivos valores de rigidez rotacional foram $4827.5 \mathrm{kNm} / \mathrm{rad}$., $5622 \mathrm{kNm} / \mathrm{rad}$. e 7844 kNm/rad.

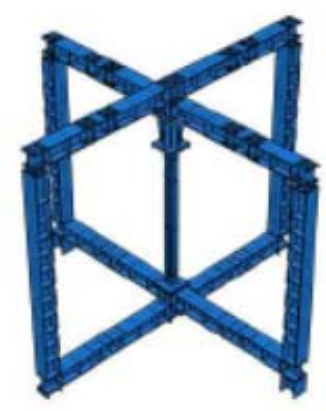

a) Vão da viga: $3 \mathrm{~m}$

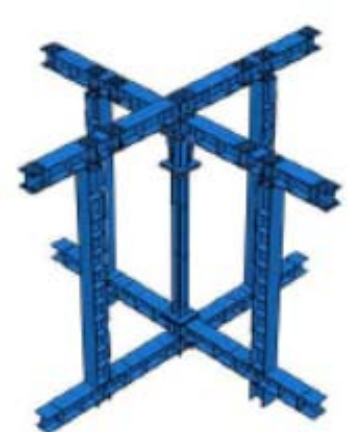

b) Vão da viga: $2 \mathrm{~m}$

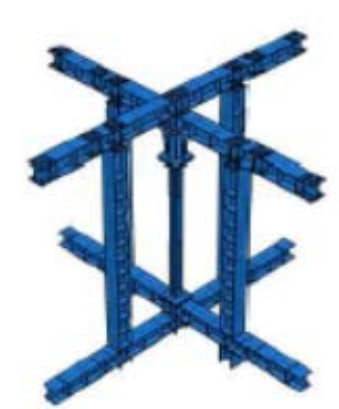

c) Vão da viga: $1,5 \mathrm{~m}$

Figura 9 - Modelo da estrutura de restrição para diferentes valores de rigidez Fonte: Correia (2011)

Foi aplicada uma força vertical constante de compressão no pilar ensaiado, com o objetivo de simular a força de serviço atuando em um pilar inserido em uma estrutura real. Essa força foi aplicada mais especificamente no nó de ligação das vigas superiores 
da estrutura de restrição, por meio de atuador hidráulico que foi fixado a um pórtico de reação bidimensional, externo à estrutura de restrição.

Para que a força aplicada não fosse parcialmente distribuída aos pilares periféricos, as ligações entre as vigas superiores e os pilares da estrutura de restrição foram realizadas com barras rosqueadas, cujas porcas foram desparafusadas antes da aplicação da carga, como mostra a Figura 10. Assim, as vigas superiores encontravam-se totalmente livres para se deslocar na vertical, permitindo total transferência da força para os pilares ensaiados. Uma vez que a força desejada fosse alcançada, as porcas eram parafusadas de forma a fornecer restrição durante o ensaio.

Após a aplicação da força e ajustado o sistema de restrição, iniciou-se o aquecimento do elemento por meio de um forno modular composto por dois módulos de $1 \mathrm{~m}$ de altura e outro com $0,5 \mathrm{~m}$. Os módulos foram superpostos um ao outro formando uma câmara de 1,5 $\mathrm{m} \times 1,5 \mathrm{~m} \times 2,5 \mathrm{~m}$ em volta dos elementos a serem ensaiados. $O$ forno aquece os elementos por meio do calor gerado pelas resistências elétricas distribuídas nas quatro paredes do mesmo.
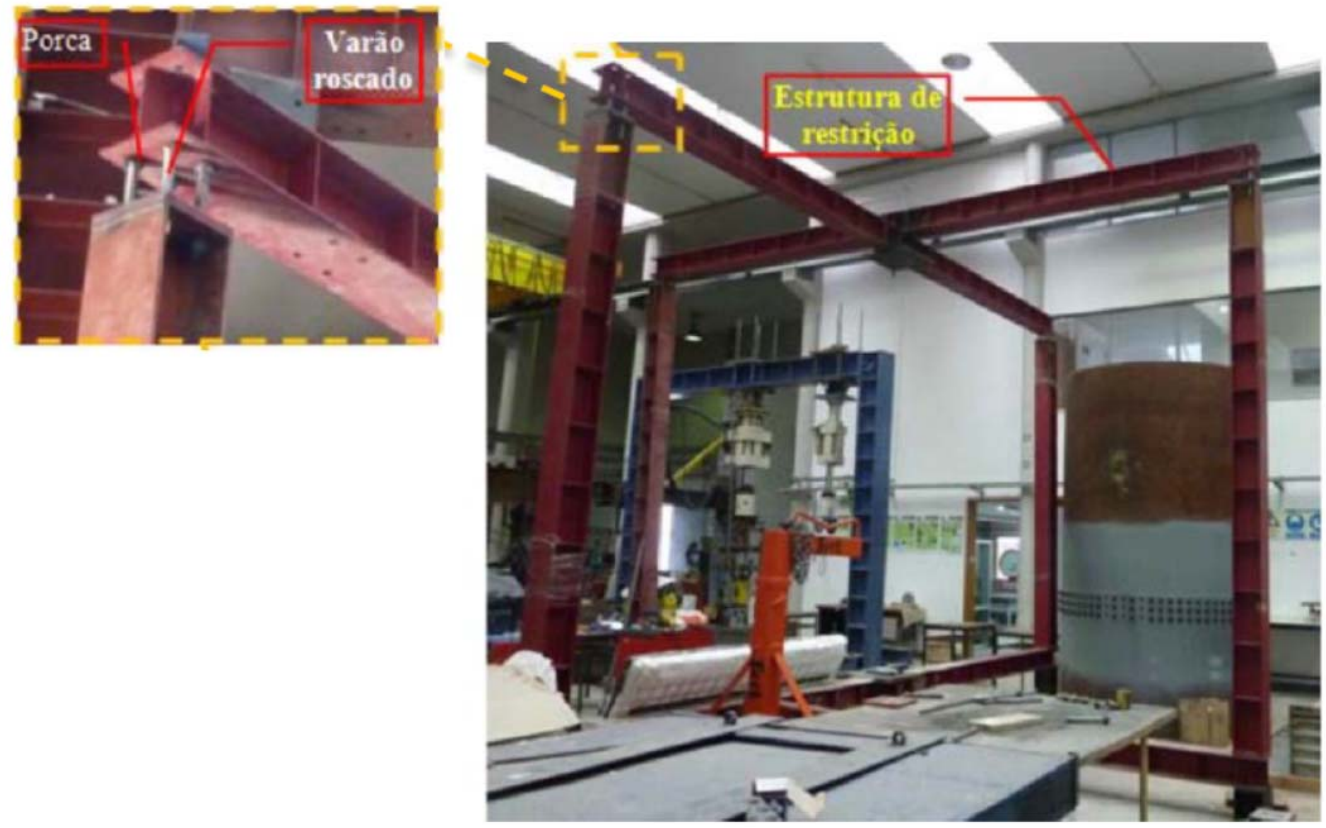

Figura 10 - Detalhe das ligações entre as vigas superiores e os pilares da estrutura de restrição

Fonte: Almeida (2012)

Os ensaios terminavam quando a força de restrição tornava a alcançar o valor da força inicialmente aplicada aos elementos. A curva de aquecimento do forno buscou seguir a curva de incêndio-padrão ISO 834-1:1999. De forma a reduzir a inércia térmica inicial, 
foi realizado um pré-aquecimento antes do início de cada ensaio. Assim, ao invés de 20 ${ }^{\circ} \mathrm{C}$, o ensaio é iniciado quando a temperatura do forno está próxima de $150{ }^{\circ} \mathrm{C}$, de forma a gerar uma curva de aquecimento mais próxima da curva de incêndio ISO 834, como mostra a Figura 11.

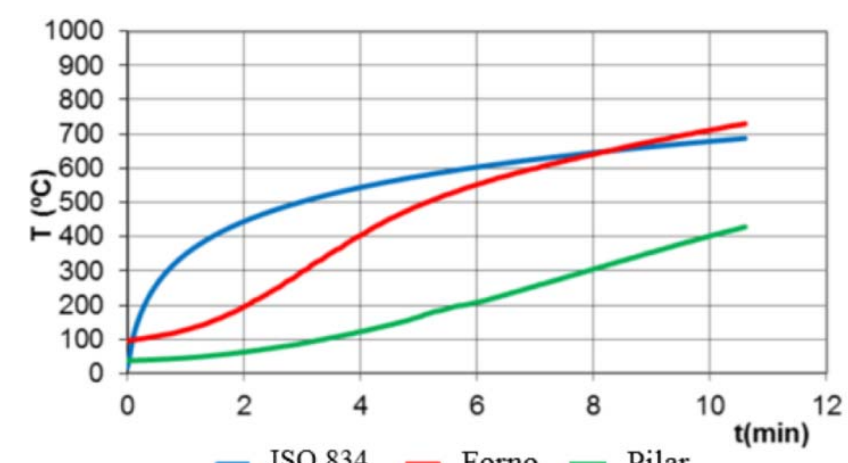

Figura 11 - Distribuição da temperatura no pilar ensaiado HEA160-K13-L70 Fonte: Correia (2011)

Foram executados 12 ensaios em pilares com força centrada. A condição de apoio foi composta por chapas de apoio quadradas com 450x450 $\mathrm{mm}$ e $30 \mathrm{~mm}$ de espessura, com 4 furos para parafusos M24, para criar uma ligação semirrígida. O comprimento dos pilares foi de 2,94 m. A força de compressão em situação de incêndio utilizada foi $30 \%$ e $70 \%$ da resistência à compressão de projeto à temperatura ambiente calculada de acordo com o EN1993-1-1:2005.

\section{Análise Numérica}

A análise numérica realizada neste estudo utilizou rotinas de programação denominadas APDL (ANSYS Parametric Development Language) de um sistema computacional comercial de elementos finitos, o pacote computacional ANSYS 17.0. Foram elaborados modelos tridimensionais, cuja análise foi executada em quatro etapas. O primeiro passo consiste de uma análise térmica transiente para determinação da ação térmica e do campo térmico nos modelos. O segundo passo se refere à análise estrutural dos modos de instabilidade, realizada por uma análise de autovalor, com o objetivo de estabelecer o modo de falha para uma determinada força crítica elástica. O terceiro passo trata de análise estrutural estática, à temperatura ambiente, considerando o comportamento não linear do material e geométrico. O quarto e último passo é direcionado à análise termestrutural com restrição axial e rotacional, onde é realizada uma análise estrutural 
considerando a variação de temperatura por meio do acoplamento dos resultados obtidos na análise térmica.

A análise térmica adotada foi baseada nos procedimentos utilizados em Regobello (2007), Kimura (2009) e Dorr (2010). Assim, devido aos bons resultados obtidos em Dorr (2010), a análise térmica foi desenvolvida utilizando o elemento finito térmico tridimensional do tipo casca SHELL 131, que permite a decomposição em camadas e informa o campo de temperaturas através do seu plano e da seção transversal.

Para a aplicação dos efeitos térmicos de convecção e radiação foi utilizado o elemento finito SURF 152, que é definido por quatro a dez nós e pelas propriedades do material, como fator de emissividade, constante Stefan-Boltzmann e coeficiente de convecção. Seu único grau de liberdade é a temperatura. Na aplicação do efeito de convecção ou radiação foi considerado um nó extra, fora da geometria do elemento, para prescrever a temperatura "ambiente"; no caso de incêndio, a temperatura dos gases. O elemento SURF 152 permite apenas um tipo de ação térmica, assim, para considerar as duas ações, foram utilizados dois elementos sobrepostos, sendo que um recebeu o carregamento de ação térmica por radiação e o outro o carregamento de ação térmica por convecção, conforme Figura 12.
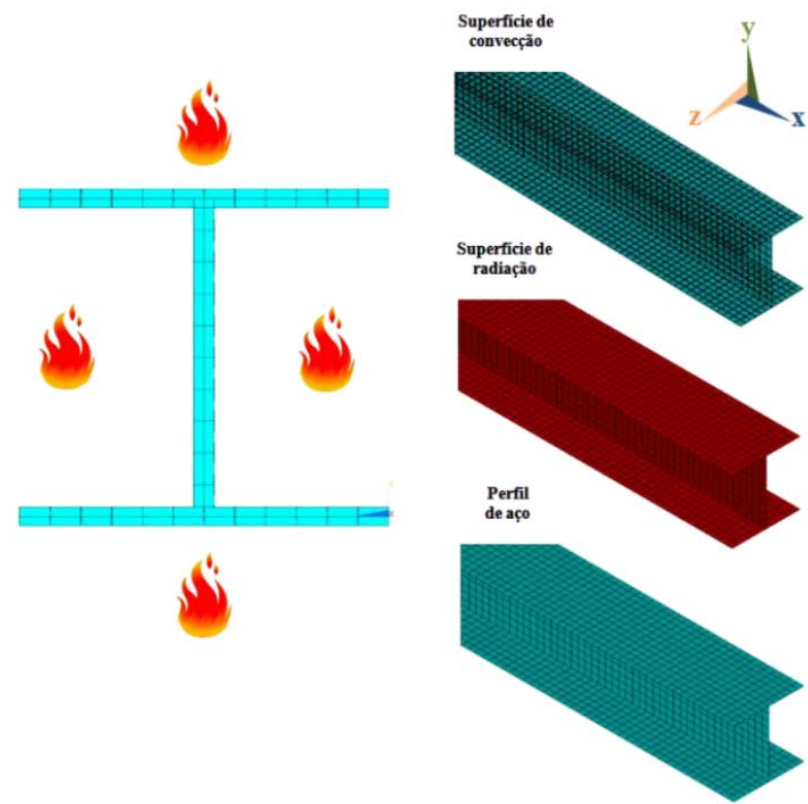

Figura 12 - Malha de elementos finitos do perfil e das superfícies de troca de calor

Conforme descrito no item 2, o forno é composto por dois módulos de 1 metro de altura e um módulo de 0,5 metros. Dessa forma, mesmo o pilar apresentando 2,94 metros, a 
ação térmica foi aplicada em apenas 2,5 metros de seu comprimento total. A Figura 13 mostra a variação de temperatura no pilar elaborado nesta pesquisa.

O modelo construído para a análise térmica foi posteriormente analisado quanto ao seu comportamento estrutural com base na resposta ao campo térmico do material. Assim, o elemento finito SHELL 131 foi substituído por um elemento equivalente estrutural, o SHELL 181, que é composto por quatro nós com seis graus de liberdade em cada nó: translação e rotação nos eixos x, y e z. De forma a representar as extremidades do modelo experimental, nessa análise foram adicionadas as placas de extremidade com dimensões de 450 x $450 \mathrm{~mm}$ e $30 \mathrm{~mm}$ de espessura e o dispositivo de medição de forças de restrição localizado no topo do pilar, como mostra a Figura 14.

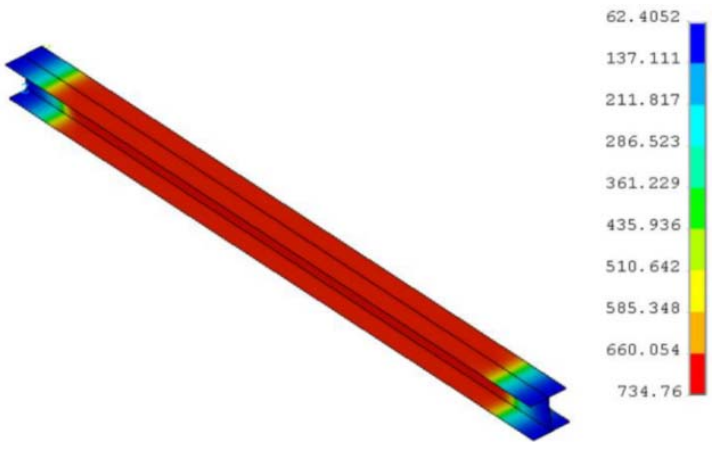

Figura 13 - Variação de temperatura no modelo numérico proposto

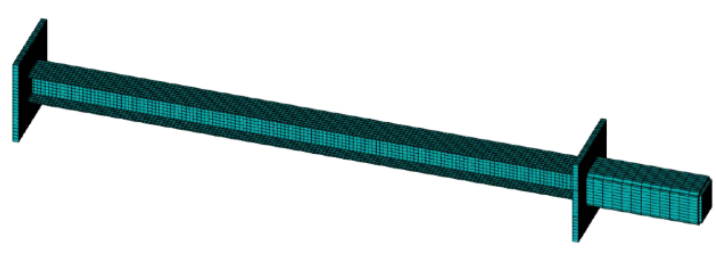

Figura 14 - Modelo numérico proposto para análise estrutural

As imperfeições geométricas iniciais consideradas no modelo foram do tipo global, portanto, não foram introduzidas imperfeições geométricas iniciais do tipo local, pois se espera que a ação térmica contribuísse para o surgimento de modos locais de falha. $A$ implementação da imperfeição geométrica foi feita de acordo com a estratégia descrita por Almeida (2007) e utilizada por Kimura (2009). Para o presente trabalho foi utilizado apenas o primeiro modo de instabilidade global, com amplitude igual a L/1000, conforme Figura 15. Durante a análise de autovalor, as condições de apoio foram definidas como uma extremidade engastada e a outra rotulada, pois, no ensaio a ação estrutural é aplicada com as vigas superiores do pórtico de restrição com as ligações desparafusadas dos pilares, ou seja, com deslocamento longitudinal livre. Portanto, os nós da placa da base do pilar foram restringidos ao deslocamento e à rotação nas direções $X, Y$ e $Z$, e os nós da placa do topo foram restringidos aos deslocamentos 
transversais, nos eixos $Y$ e $Z$, e à rotação no eixo $X$. A ação mecânica foi inserida como força axial e aplicada de forma centrada no topo do pilar.

Nas extremidades do pilar foram criadas regiões rígidas com o objetivo unir grupos de nós, definindo uma relação linear entre os graus de liberdade de cada nó. Dessa forma, aplicando a carga em um nó (nó mestre), esta será transferida adequadamente para os outros nós da região rígida. Portanto, as condições de contorno do modelo foram aplicadas apenas nos nós mestres de cada chapa de extremidade. A construção do modelo de elementos finitos para a análise estrutural seguiu o mesmo procedimento utilizado na análise térmica, de forma a manter todos os nós na mesma posição, a fim de possibilitar o acoplamento entre a análise térmica e a análise estrutural. Assim, o campo de temperaturas gerado na análise térmica foi transferido para o elemento de casca do tipo estrutural na intenção de modelar o comportamento termestrutural. Os pilares em situação de incêndio restringidos axial e rotacionalmente elaborados no presente trabalho foram representados numericamente de forma semelhante aos modelos adotados em Ali et al. (1998) e em Velarde (2008), onde as restrições são consideradas por meio de molas com diferentes valores de rigidez, como apresentado na Figura 16. As restrições axiais e rotacionais foram modeladas utilizando o elemento finito COMBIN 14, um elemento de mola com capacidade longitudinal ou de torção, em aplicações unidimensional, bidimensional ou tridimensional. A opção de mola longitudinal consiste em um elemento de tração-compressão uniaxial com até três graus de liberdade em cada nó: translações nas direções nodais $x$, y e z. Não são consideradas flexão ou torção. A opção de mola de torção consiste em um elemento puramente rotacional com três graus de liberdade em cada nó: rotações sobre os eixos nodais $x, y$, e z.

Nesta etapa da análise, as condições de apoio nos nós da placa da base do pilar foram modificadas, pois a restrição à rotação foi considerada por meio da mola rotacional. Assim, os nós permaneceram restringidos ao deslocamento nas direções $X, Y$ e $Z$, porém a rotação foi restringida somente na direção $X$, e nas direções $Y$ e $Z$ foram aplicadas molas com a restrição rotacional a ser analisada. O mesmo foi feito no topo do pilar, onde as restrições à rotação nos eixos $Y$ e $Z$ foram substituídas por molas rotacionais com a rigidez a ser estudada. Além disso, no topo do pilar também foi acrescentada uma 
mola axial na direção x para considerar a restrição axial do pilar. Cada mola foi aplicada no nó mestre da região rígida criada nas extremidades do modelo, com nós coincidentes.

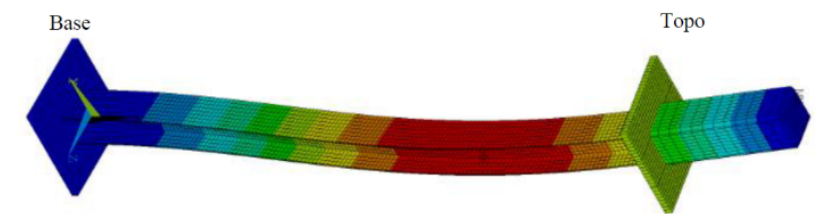

Figura 15 - Primeiro modo de instabilidade global

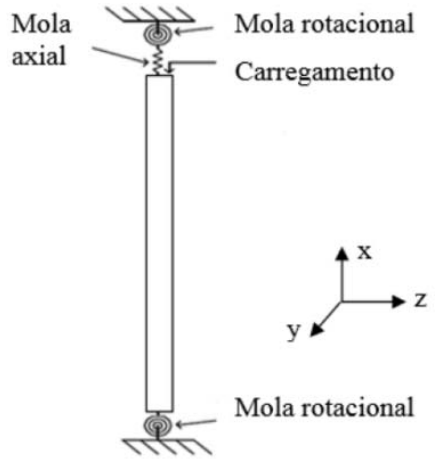

Figura 16 - Representação do modelo numérico adotado Fonte: Ali et al. (1998). Modificada pelos autores.

A ação mecânica foi inserida em termos de força axial e mantida constante durante o aquecimento. Para a validação do modelo desenvolvido, a magnitude dessa ação correspondeu à mesma utilizada por Correia (2011), cujos valores correspondem a $30 \%$ e $70 \%$ da força normal resistente de cálculo à temperatura ambiente. Verificou-se que, ao aplicar a força de compressão, o pilar restringido sofreu uma deformação axial inicial, fazendo com que a mola de restrição axial fosse solicitada à tração, absorvendo parte da força de forma proporcional ao valor de sua rigidez. Para contornar essa situação foi utilizada a mesma estratégia considerada em Dorr (2010), onde o nó superior da mola com rigidez axial foi restringido ao deslocamento longitudinal, porém, foi dado a ele um deslocamento inicial igual ao sofrido pelo pilar devido à força aplicada. Ou seja, o valor do deslocamento inicial do pilar foi utilizado como "recalque" inicial do nó superior da mola de restrição para que a expansão térmica do pilar solicite a restrição axial à compressão desde o início e não apenas quando o topo do pilar retornar ao ponto inicial (sem deformação devido à força aplicada).

\section{Validação do modelo numérico}

Para a validação do modelo numérico proposto, foram analisados seis pilares dentre os quatorze ensaiados por Correia (2011), todos com o perfil HEA160 e força centrada. As propriedades do material inerentes ao modelo térmico, condutividade térmica, calor específico e coeficiente de dilatação térmica, foram definidas com base no EN 1993-1- 
2:2005, como utilizado por Correia (2011). A constante de troca de calor por convecção da superfície exposta à ação térmica foi considerada igual a $25 \mathrm{~W} / \mathrm{m}^{2}{ }^{\circ} \mathrm{C}$. Em relação às variáveis que definem a troca de calor por radiação, foram definidas a constante StefanBoltzmann igual a $5,67 \times 10-8 \mathrm{~W} / \mathrm{m}^{2} \mathrm{~K} 4$ e a emissividade do perfil com valor de $\varepsilon=0,8$. A massa específica do aço pode ser considerada independente da variação da temperatura, e será admitida com valor igual a $7850 \mathrm{~kg} / \mathrm{m}^{3}$. A curva apresentada na Figura 11 é o único registro da evolução da temperatura dos gases dentro do forno registrada em Correia (2011). Por falta de outros dados, todos os modelos validados foram analisados com essa mesma curva.

Devido ao pré-aquecimento do forno realizado para que a curva de aquecimento ficasse mais próxima da curva ISO 834, a temperatura inicial dos pilares no ensaio variou em cada seção. Assim, para a validação, a temperatura inicial das seções do pilar no interior do forno foi retirada da curva média de evolução da temperatura dos pilares apresentada na Figura 11, utilizando então $45^{\circ} \mathrm{C}$. As seções S1 e S2 que estão fora do forno apresentaram temperatura inicial igual a $20^{\circ} \mathrm{C}$. A Figura 17 mostra a comparação entre a evolução da temperatura do pilar apresentados no modelo experimental e no modelo proposto. Nota-se que, apesar de a curva de aquecimento utilizada ter sido uma curva média de apenas um ensaio, desconsiderando a variação de temperatura de cada módulo do forno e em cada ensaio particularmente, os valores obtidos na análise numérica se aproximaram dos valores obtidos experimentalmente.

$\mathrm{Na}$ análise termestrutural, a temperatura introduz deformações térmicas no modelo estrutural, mas as deformações estruturais geralmente não afetam a distribuição de temperatura e então não há necessidade de interação entre a solução das duas análises. Assim, o método utilizado neste trabalho foi o método sequencial, realizando inicialmente a análise térmica e, posteriormente, acoplando à análise estrutural os resultados obtidos na primeira análise. $\mathrm{Na}$ análise estrutural à temperatura ambiente, foram adotadas as seguintes propriedades mecânicas: módulo de elasticidade longitudinal igual a $210 \mathrm{GPa}$, coeficiente de Poisson igual a 0,3 e resistência ao escoamento conforme valores apresentados por Correia (2011). De forma a considerar a não linearidade do material, a curva de tensão versus deformação foi representada 
por uma curva multilinear que segue o critério de plastificação de von Mises, para materiais isotrópicos elastoplásticos com encruamento.

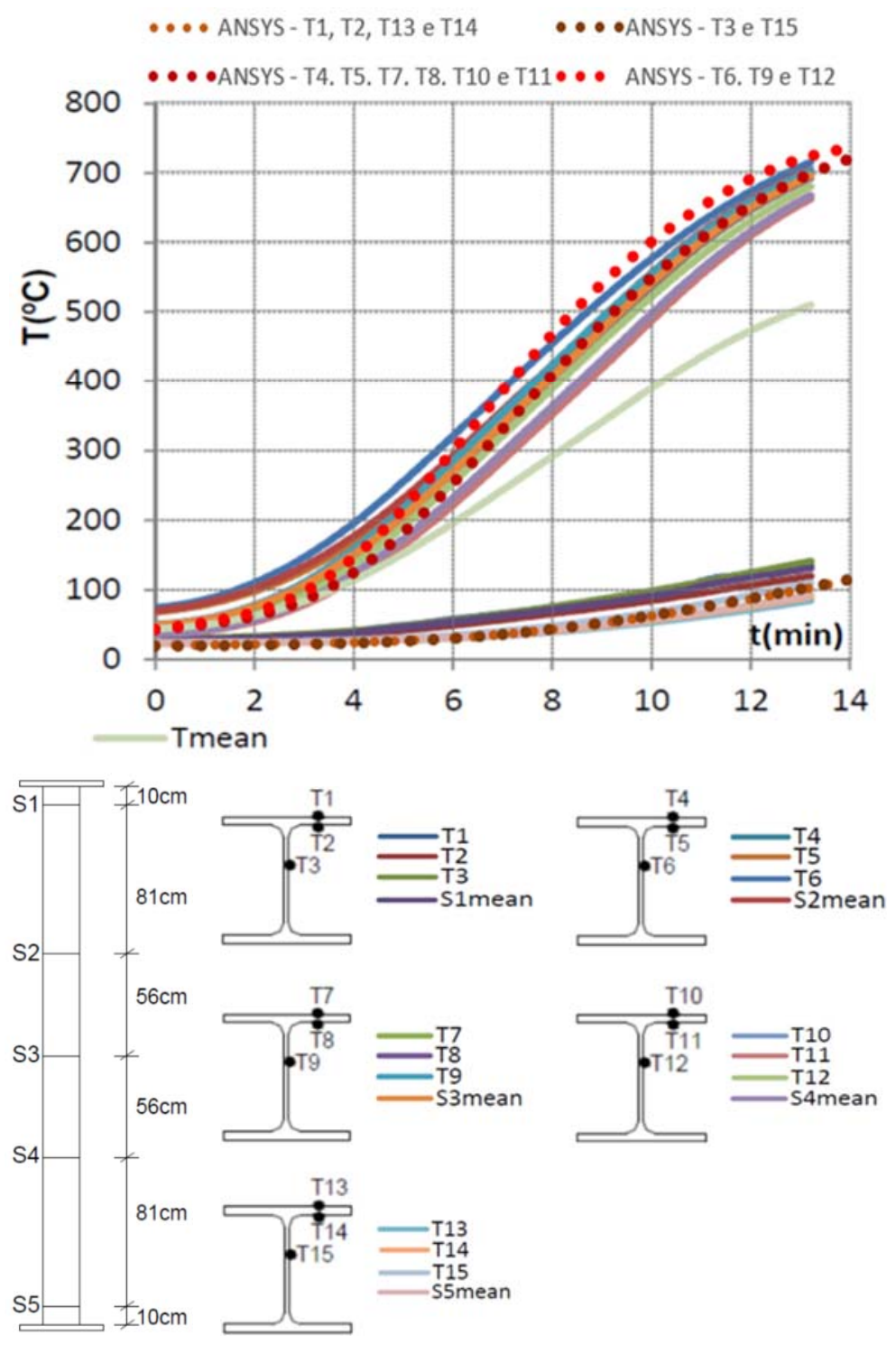

Figura 17 - Evolução da temperatura do pilar dos modelos numérico e experimental para o pilar HEA160-K45-L30.

Os resultados do modelo numérico proposto, elaborado no ANSYS, foram comparados aos resultados obtidos no ensaio (Figura 18), para o deslocamento axial e as forças de restrição no topo do pilar. Uma boa concordância entre os resultados experimentais e as simulações numéricas pode ser observada. $P_{0}$ representa a força inicial aplicada no pilar e $\mathrm{P}$ representa a força inicial mais a força de restrição gerada no instante considerado. Os valores do deslocamento axial obtidos no modelo numérico foram similares aos obtidos no ensaio, porém com valores um pouco maiores durante quase todo o período estudado. Acredita-se que a diferença de valores está no fato de que o 
modelo numérico utilizou temperatura uniforme em todas as seções do pilar, sem considerar as diferenças de temperatura obtidas no ensaio, onde as seções S3 e S4 apresentaram menores temperaturas que a seção S2. A Figura 19 mostra a deformada do pilar no modelo numérico proposto e a do modelo experimental, onde se observa que o comportamento da estrutura em ambos os modelos foi similar, apresentando instabilidade local nas extremidades e no meio do pilar.

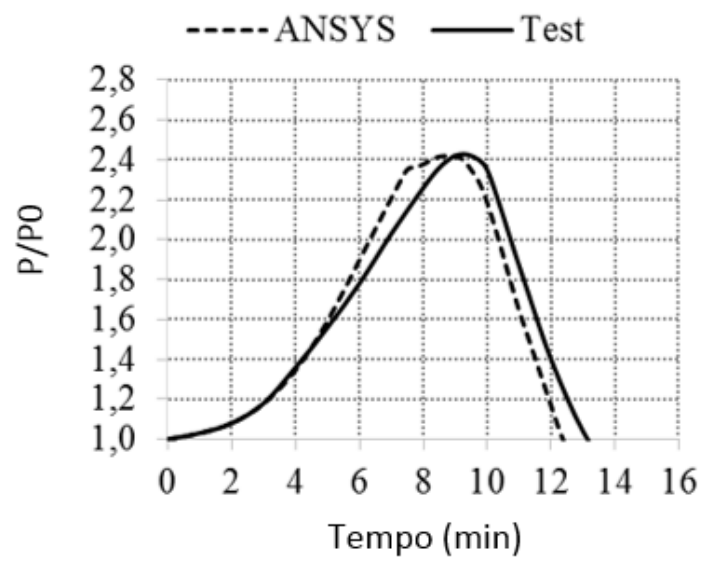

a) Forças de restrição

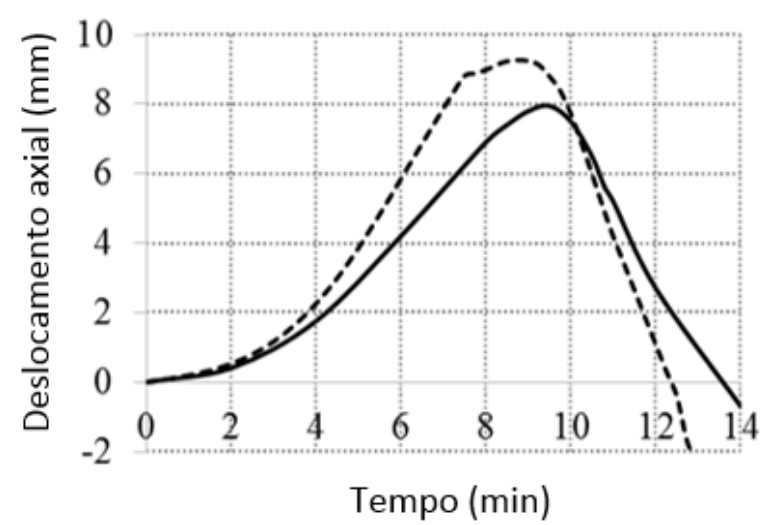

b) Deslocamento axial

Figura 18 - Comparação do resultado do ensaio obtido em (2011) e o resultado obtido na análise numérica elaborada nesta pesquisa

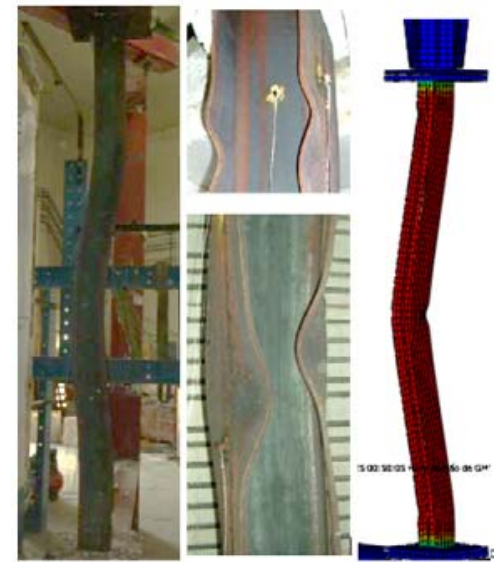

a) Análise experimental e numérica Correia (2011)

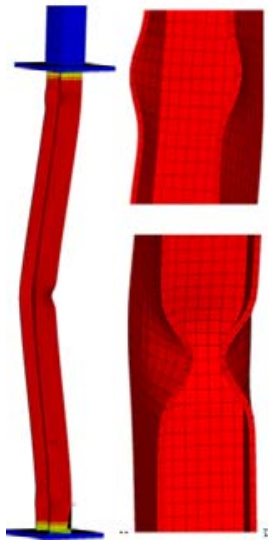

b) Modelo numérico elaborado nesta pesquisa

Figura 19 - Comparação entre deformadas do pilar obtidas em ensaio e modelagem numérica por Correia (2011) e modelagem numérica elaborada nesta pesquisa

\section{Conclusão}

O presente trabalho apresentou uma explicação do comportamento de pilares de aço em situação de incêndio com restrição axial e rotacional. Em seguida foi realizada uma 
simulação do comportamento de pilares de aço com seção I em situação de incêndio sob compressão centrada, com restrição axial e rotacional. Foram elaborados modelos numéricos em elementos finitos utilizando o programa computacional ANSYS, para representar o comportamento não linear, geométrico e do material, do pilar restringido a altas temperaturas.

Com o objetivo de validar resultados do campo térmico por meio de comparação entre resultados obtidos em uma pesquisa feita anteriormente, este trabalho apresentou um modelo em campo tridimensional de temperaturas que foi capaz de reproduzir de forma coerente a temperatura obtida experimentalmente por Correia (2011). Com relação às análises em temperatura ambiente, o modelo elaborado com o elemento finito SHELL181 apresentou resultados satisfatórios quando comparado ao modelo experimental considerado. O modelo validado será usado no desenvolvimento de futuras pesquisas relacionadas ao tema.

\section{Agradecimentos}

Agradece-se ao PPGEC-UFES, à FAPES (ES), à FAPESP (Processo 2015/21602-4), à CAPES e ao CNPq.

\section{Referências bibliográficas}

ALI, F.A.; O'CONNOR, D. J. Structural performance of rotationally restrained steel columns in fire. Fire Safety Journal 36: 679-691, (2001).

ALI, F.A.; SHEPHERD, P.; RANDALL, M.; SIMMS, I.W.; O'CONNOR, D. J.; BURGESS, I. The effect of axial restraint on the fire resistance of steel columns. Journal of Constructional Steel Research 46: 305-306, (1998).

ALMEIDA, S.J.C. Análise numérica de perfis de aço formados a frio comprimidos considerando imperfeições geométricas iniciais. Dissertação (Mestrado) - Escola de Engenharia de São Carlos, Universidade de São Paulo, São Carlos, (2007).

ALMEIDA, S.J.C. Análise do comportamento a temperaturas elevadas de elementos de aço formados a frio comprimidos considerando restrição ao alongamento térmico. Tese (Doutorado) - Escola de Engenharia de São Carlos, USP, São Carlos, (2012). 
ASSOCIAÇÃO BRASILEIRA DE NORMAS TÉCNICAS - ABNT NBR 8800 Projeto de estruturas de aço e mistas de aço e concreto de edifícios. Rio de Janeiro, (2008).

ABNT. NBR 14323 Projeto de estruturas de aço e de estruturas mistas de aço e concreto de edifícios em situação de incêndio. Rio de Janeiro, (2013). CORREIA, A. J. P. M. Fire resistance of steel and composite steel-concrete columns. Coimbra. Tese (Doutorado). Departamento de Engenharia Civil - Faculdade de Ciências e Tecnologia - Universidade de Coimbra, (2011).

DORR, J. B. Modelos numéricos de pilares de aço em situação de incêndio considerando a influência da restrição axial. Dissertação (Mestrado) - Escola de Engenharia de São Carlos - Universidade de São Paulo, (2010).

EUROPEAN COMMITTEE FOR STANRDARDIZATION. EN 1993 1-2 Eurocode 3 - Design of steel structures - Part 1-2: General rules - Structural fire design. Brussels, (2005).

INTERNATIONAL ORGANIZATION FOR STANDARDIZATION. Fire-resistance tests Elements of building construction - Part 1: General requirements. ISO 834-1 (1999). KIMURA, E. F. A. Análise termoestrutural de pilares de aço em situação de incêndio. São Carlos. Dissertação (Mestrado) - Escola de Engenharia de São Carlos - USP, (2009).

NEVES, I. C. The critical temperature of steel columns with restrained thermal elongation. Fire Safety Journal, 24:211-227, Elsevier Science, (1995).

REGOBELLO, R. Análise numérica de seções transversais e de elementos estruturais de aço e mistos de aço e concreto em situação de incêndio. São Carlos. Dissertação (Mestrado) - Escola de Engenharia de São Carlos - Universidade de São Paulo, (2007).

SHEPHERD, P. G. AND BURGESS, I. W. On the buckling of axially restrained steel columns in fire. Engineering Structures, 33: 2832-2838, (2011).

VELARDE, J. S. S. Sobre o comportamento de pilares de aço em situação de incêndio. Dissertação (Mestrado). Escola Politécnica da Universidade de São Paulo, (2008).

WANG, Y. C. Steel and composite structures, behaviour and design for fire safety. Londres, Spon Press, (2002).

WEBBER, A.; ORR, J. J.;SHEPHERD, P.; CROTHERS, K. The effective length of columns in multi-storey frames. Engineering Structures 102, (2015). 